\title{
Effects of Sulfate-Rich Mineral Water on Functional Constipation: A Double-Blind, Randomized, Placebo- Controlled Study
}

\author{
Johannes Naumann ${ }^{\mathrm{a}}$ Catharina Sadaghiani ${ }^{\mathrm{a}}$ Felix Alt ${ }^{\mathrm{b}}$ Roman Huber ${ }^{\mathrm{c}}$ \\ ${ }^{a}$ Interdisciplinary Center for Treatment and Research in Balneology, Institute for Environmental Health Sciences and Hospital Infection \\ Control, Medical Faculty, University Medical Center Freiburg, Freiburg i.Br., Germany; \\ b analyze \& realize $\mathrm{GmbH}$, Clinical Research, Berlin, Germany; \\ ${ }^{\mathrm{c}}$ Center for Complementary Medicine, Institute for Environmental Health Sciences and Hospital Infection Control, Medical Faculty, \\ University Medical Center Freiburg, Freiburg i.Br., Germany
}

\section{Keywords}

Functional constipation · Bowel movements · Mineral water . Sulfate $\cdot$ Magnesium

\section{Summary}

Background: Magnesium sulfate has a long tradition as a laxative. It osmotically prevents water absorption in the large bowel and thus leads to an acceleration of the intestinal transit and better stool consistency. We wanted to investigate the efficacy of a carbonated calcium/magnesium sulfate-rich natural mineral water in subjects with functional constipation (FC). Patients and Methods: In this double-blind, randomized, placebo-controlled study, subjects with FC (Rome III criteria) received $1 \mathrm{l} /$ day $(4 \times 250 \mathrm{ml})$ of mineral water (Ensinger Schiller Quelle) or carbonated tap water (placebo) for 6 weeks. The primary endpoint was the change in the frequency of bowel movements per week between baseline and visit 4 (after 6 weeks). The prespecified main secondary endpoint was the change in the frequency of bowel movements per week between baseline and visit 3 (after 3 weeks). Results: Efficacy was analyzed in 100 subjects (intention-to-treat). After 6 weeks of treatment there was no statistical difference between the groups $(p=0.163)$. However, statistical significance was reached after 3 weeks, with an increase in the frequency of bowel movements per week of $2.02 \pm 2.22$ for the mineral water group compared to $0.88 \pm 1.67$ for the placebo group ( $p=0.005$ ). Conclusions: A 3-week treatment with $1 \mathrm{I} /$ day of the sulfate-rich mineral water improved the frequency of bowel movements in subjects with FC compared with tap water; however, the difference was no longer significant after 6 weeks. Further evaluation in rigorously designed clinical studies will be necessary to validate the impact of sulfate-rich natural mineral water on FC.

(c) 2016 S. Karger GmbH, Freiburg

The authors take responsibility for all aspects of the reliability and freedom from bias of the data presented and their discussed interpretation.

\section{Schlüsselwörter}

Funktionelle Obstipation - Stuhlgang · Mineralwasser . Sulfat · Magnesium

\section{Zusammenfassung}

Hintergrund: Die Verwendung von Magnesiumsulfat als Laxans hat eine lange Tradition. Es verhindert osmotisch die Wasseraufnahme im Dickdarm und bewirkt so eine Beschleunigung der Darmtätigkeit und eine verbesserte Stuhlkonsistenz. In dieser Studie wird die Wirksamkeit eines kohlensäurehaltigen Mineralwassers, reich an Magnesium, Sulfat und Calcium, bei Patienten mit funktioneller Obstipation (FO) untersucht. Patienten und Methoden: In dieser randomisierten, placebokontrollierten Doppelblindstudie erhielten Patienten mit FO (Rom-III-Kriterien, 2-4 Stuhlgänge pro Woche) über einen Zeitraum von 6 Wochen täglich 1 I $(4 \times 250 \mathrm{ml})$ sulfatreiches Mineralwasser (Ensinger Schiller Quelle) oder kohlensäurehaltiges Leitungswasser (Placebo). Primäres Zielkriterium war die Veränderung der Stuhlfrequenz pro Woche zwischen Baseline und Visite 4 (nach 6 Wochen) im Vergleich zu Placebo. Sekundäres vorher festgelegtes Hauptzielkriterium war die Veränderung der Stuhlfrequenz pro Woche zwischen Baseline und Visite 3 (nach 3 Wochen). Ergebnisse: Insgesamt wurden 100 Patienten eingeschlossen und randomisiert (Intention-to-Treat-Analyse). Nach 6-wöchiger Behandlung gab es keinen signifikanten Unterschied zwischen den Gruppen ( $p=0,163$ ). Statistische Signifikanz zeigte sich nach 3 Wochen mit einer Veränderung der Stuhlfrequenz pro Woche um 2,02 $\pm 2,22$ für die Mineralwasser-Gruppe im Vergleich zu 0,88 $\pm 1,67$ für die Placebo-Gruppe $(p=0,005)$. Schlussfolgerungen: Nach 3-wöchiger Anwendung verbesserte das Trinken von täglich 1 I sulfathaltigem Mineralwasser die Stuhlfrequenz bei Patienten mit FO, wobei der Unterschied nach 6 Wochen nicht mehr signifikant war. Um die Wirkung von sulfathaltigem Mineralwasser bei FO zu validieren, sind gut geplante Studien mit größerer Probandenzahl und längerem Beobachtungszeitraum nötig.

\begin{tabular}{ll}
\hline KARGER & $\begin{array}{l}\text { Accessible online at: } \\
\text { www.karger.com/fok }\end{array}$ \\
Fax +497614520714 & $\begin{array}{l}\text { This article is licensed under the Creative Commons Attribution- } \\
\text { Information@Karger.com }\end{array}$ \\
$\begin{array}{l}\text { NonCommercial-4.0 International License (CC BY-NC) (http:// } \\
\text { www.karger.com/Services/OpenAccessLicense). Usage and distri- } \\
\text { bution for commercial purposes requires written permission. }\end{array}$
\end{tabular}

Dr. Johannes Naumann

Interdisciplinary Center for Treatment and Research in Balneology, Institute for Environmental Health Sciences and Hospital Infection Control

Medical Faculty, University Medical Center Freiburg

Breisacher Straße 115b, 79106 Freiburg i.Br., Germany

johannes.naumann@uniklinik-freiburg.de 
Table 1. Rome III Diagnostic Criteria fo Functional Constipation [17]
Criteria fulfilled for the last 3 months with symptom onset at least 6 months prior to diagnosis

1. Must include 2 or more of the following:

a) Straining during at least $25 \%$ of the defecations

b) Lumpy or hard stools in at least $25 \%$ of the defecations

c) Sensation of incomplete evacuation for at least $25 \%$ of the defecations

d) Sensation of anorectal obstruction/blockage for at least $25 \%$ of the defecations

e) Manual maneuvers to facilitate at least $25 \%$ of the defecations (e.g., digital evacuation, support of the pelvic floor)

f) Fewer than 3 defecations per week

2. Loose stools are rarely present without the use of laxatives

3. Insufficient criteria for irritable bowel syndrome

\section{Introduction}

The prevalence of constipation is about $14 \%$ [1], and that of functional constipation (FC) 4.6\% [2], with differences according to the criteria applied: region, age, or gender [3]. Chronic constipation impairs the quality of life and leads to direct costs ranging from USD 1,912 to USD 7,522 per year [4].

Initial management of chronic constipation should include lifestyle changes and increased fiber and fluid intake. More active interventions include the use of laxatives and other medications, irrigation, and biofeedback therapy [4]. A recent survey supported the treatment of constipation with increased liquid intake rather than physical exercise or dietary fibers [5]

The medicinal use of water is probably as old as mankind, and drinking water cures have been used for digestive problems since ancient times [6]. Especially sulfate-rich mineral water is traditionally used for treating FC. Magnesium sulfate osmotically prevents water absorption in the large bowel, thus leading to an acceleration of the intestinal transit and better stool consistency [7]. Furthermore, it is assumed to have beneficial effects on bile acids, liver function, blood lipids, and the gut microbiota [8-10].

Its positive effects have been proven in several, mostly uncontrolled older studies $[9,11-13]$. Three newer double-blind, randomized studies investigating the effects of sulfate-rich mineral water on chronic constipation found positive effects for otherwise healthy subjects [14], women [15] and infants [16].

The present study aimed to assess the efficacy and safety of giving 11 of sulfate-rich mineral water 4 times daily $(250 \mathrm{ml})$ for 6 weeks to adults with FC according to the Rome III criteria (table 1) [17].

\section{Methods}

\section{Study Overview}

This study is reported according to the CONSORT guidelines (Consolidated Standards of Reporting Trials) for the presentation of clinical trials, as summarized in table 2 [18]. This was a 6-week randomized, double-blind, placebo-controlled single-center study to evaluate the efficacy and safety of Ensinger Schiller Quelle mineral water $(11 /$ day, $4 \times 250 \mathrm{ml})$. The study was conducted in accordance with Good Clinical Practice (GCP) guidelines (CPMP/ICH/135/95; Topic E6 (R1); and GCP-V), the Declaration of Helsinki, and local laws and regulations (AMG (Arzneimittelgesetz; Medicinal Products Act, The Drug Law)). The protocol was reviewed and approved by the national competent authority (BfArM (Bundesinstitut für Arzneimittel und Medizinprodukte; Federal Institute for Drugs and Medical Devices), Germany) and by the local ethics committee (LAGeSo, Germany; 13/0134-EK11). The study was prospectively registered in the European Clinical Trials Database (EudraCT 2013-000861-36). Participants gave their written informed consent before inclusion. All authors had access to the study data and reviewed and approved the final manuscript.

\section{Study Participants}

Enrollment (Dr. Ilona Uebelhack; analyze \& realize) was during a period of 12 months from July 2013 to July 2014 in Berlin, Germany. Inclusion criteria were: age 18-64 years, body mass index (BMI) $<35 \mathrm{~kg} / \mathrm{m}^{2}$, bowel movements on 2-4 days per week during the last 3 months (according to the subject's own statement), and a diagnosis of FC according to the Rome III criteria. Further inclusion criteria were: subjects should commit to adhering to their former diet and physical activity; they should be used to consuming at least 11 of water (including tea) or mineral water daily and should use the study water only for themselves. The use of contraception methods was an additional criterion for women of childbearing age. Exclusion criteria (among others): clinically relevant excursions of laboratory parameters; irritable bowel syndrome; acute or chronic disease of the gastrointestinal tract; presence of occult blood on screening; abdominal surgery within the last 6 months prior to study start; use of any preparations that could affect the gastrointestinal tract (e.g., probiotics, laxatives, enema, constipating drugs, etc.) during the last 2 weeks and during the study; magnesium and calcium supplementation during the study; intake of mineral water other than the investigational product during the study (complete list see Online Supplemental Text 1; www.karger.com/?DOI=449436).

Recruitment took place via public advertisements. Participants got financial incentives (EUR 35 for visit 1 and EUR 50 each for visits 2-4).

\section{Interventions}

The 6-week treatment period was preceded by a 1-week run-in phase after the screening visit. A self-evaluation diary was completed by the participants during this period. To undergo randomization at the end of the run-in phase, participants had to have complete bowel movements on 2-4 days per week and a daily intake of 11 of water/tea or mineral water (according to their diaries). The rationale was to include patients with mildly and moderately reduced bowel movement frequency, as the investigational product was expected to be most appropriate for this population.

The participants had to drink $250 \mathrm{ml}$ of room temperature mineral water or tap water (placebo) 4 times daily: 30 min before breakfast, during the morning, $30 \mathrm{~min}$ before lunch, and $30 \mathrm{~min}$ before supper. Both the mineral water and placebo were provided in identical 1-1 bottles.

The mineral water has a total mineralization content of 2,666 mg/l (573 mg/l calcium, $105 \mathrm{mg} / \mathrm{l}$ magnesium, 1,535 mg/l sulfate, and others) and 2,650 mg/l carbon dioxide added (for details see Online Supplemental Table 1; www. karger.com/?DOI=449436). The placebo was tap water with a total mineralization content of $108 \mathrm{mg} / \mathrm{l}$ ( $48 \mathrm{mg} / \mathrm{l}$ calcium, $8 \mathrm{mg} / \mathrm{l}$ magnesium, $34 \mathrm{mg} / \mathrm{l}$ sulfate, and others) and 2,650 mg/l carbon dioxide added (for details see Online Supplemental Table 2; www.karger.com/?DOI=449436). 
Table 2. Study design

\begin{tabular}{|c|c|c|c|c|}
\hline & \multirow{2}{*}{$\begin{array}{l}\text { Run-in } \\
\text { Visit 1, } \\
\text { screening }\end{array}$} & \multicolumn{3}{|l|}{ Treatment } \\
\hline & & $\begin{array}{l}\text { Visit 2, } \\
\text { baseline/randomization }\end{array}$ & Visit 3 & Visit 4 \\
\hline Week & 0 & 1 & 3 & 6 \\
\hline $\begin{array}{l}\text { Weight, waist and } \\
\text { hip circumferences }\end{array}$ & $\mathrm{x}$ & & & $\mathrm{x}$ \\
\hline $\begin{array}{l}\text { Pulse rate, } \\
\text { blood pressure }\end{array}$ & $\mathrm{x}$ & $\mathrm{x}$ & $\mathrm{x}$ & $\mathrm{x}$ \\
\hline $\begin{array}{l}\text { Daily diary: BSFS, } \\
\text { VAS, WI, CE }\end{array}$ & $\mathrm{x}$ & $\mathrm{x}$ & $\mathrm{x}$ & $\mathrm{x}$ \\
\hline $\begin{array}{l}\text { Questionnaires: } \\
\text { GIQLI, SF-12 }\end{array}$ & & $\mathrm{x}$ & $\mathrm{x}$ & $\mathrm{x}$ \\
\hline Blood draw $w^{b}$ & $\mathrm{x}$ & & & $\mathrm{x}$ \\
\hline Stool analysis ${ }^{c}$ & $\mathrm{x}$ & & & $\mathrm{x}$ \\
\hline $\begin{array}{l}\text { Global judgement } \\
\text { of efficacy/safety }\end{array}$ & & & & $\mathrm{x}$ \\
\hline Adverse events & & $\mathrm{x}$ & $\mathrm{x}$ & $\mathrm{x}$ \\
\hline
\end{tabular}

BSFS = Bristol Stool Form Scale (number and type of stools); VAS = Visual Analogue Scale (degree of pain and degree of pressing during bowel movement); $\mathrm{WI}=$ water intake (date/quantity); $\mathrm{CE}=$ complete evacuation (bowel movements with sensation of complete evacuation (yes/no)); GIQLI = Gastrointestinal Quality of Life Index; SF-12 = Short Form Health Survey-12.

a Self-evaluation diary: Distribution/redemption.

'Blood analysis: Liver function (alanine transaminase, aspartate aminotransferase, $\gamma$-glutamyltransferase, alkaline phosphatase, bilirubin) and lipids (triglycerides, total cholesterol, high-density lipoprotein, lowdensity lipoprotein).

'Stool analysis: Semi-quantitative assessment of potentially pathological (E. coli (atypical), Enterobacteriaceae sp. (not differentiated), Clostridium sp., Gram-negative bacteria (non-enterics, not differentiated), Staphylococcus sp., $\beta$-hemolytic streptococci, Bacillus sp.) and potentially beneficial (Lactobacillus spp., Bifidobacterium spp., Bacteroidetes, Enterococcus spp., E. coli) bacteria, as well as yeast-like fungi and molds (Geotrichum sp.).

\section{Measurements}

Medical history and constipation episodes (Rome III criteria, onset of symptoms, dietary habits, physical activities, and previous and current treatments) were recorded at inclusion; the weight and waist and hip circumferences at visits 1 and 4; pulse rate and blood pressure at each visit; blood draws and stool sampling at visits 1 and 4 . Laboratory parameter determinations were performed with standard methods at MDI Laboratorien GmbH, Berlin, Germany (DIN EN ISO 15189:2007 certified) (table 2).

\section{Diaries and Questionnaires}

From the start of the 1-week run-in period through the end of the study, the participants recorded in self-evaluation diaries: 1) the number and type of stools (Bristol Stool Form Scale; BSFS) [19], 2) the degree of pain and pressing during bowel movement (Visual Analogue Scale (VAS) 0-10), 3) the date and quantity of water intake, and 4) the bowel movements with sensation of complete evacuation (yes/no).

At baseline, week 3, and week 6, the gastrointestinal quality of life was evaluated with the Gastrointestinal Quality of Life Index (GIQLI) [20], a standardized German psychometric test that permits the evaluation of 5 different dimensions of gastrointestinal quality of life (classified as 'symptoms', 'emotions', 'physical functions', 'social functions', and 'inconvenience of medical treatment'). The GIQLI comprises 36 items to be answered by a 5-point rating scale, in which ' 0 ' represents an extreme problem/symptom and ' 4 ' represents the absence of a problem/symptom.

A validated generic instrument, the Short Form Health Survey-12 (SF-12) [21] was used to assess physical as well as mental health-related quality of life on a scale of $0-100$, with higher scores indicating a better general well-being. A global evaluation of efficacy and tolerance by both investigators and subjects was performed at the end of the treatment, using a scale of 'very good', 'good', 'moderate', and 'poor'.

\section{Safety Parameters}

Data from participants who took at least 1 dose of the study water were included in the safety assessment. Adverse events (AEs) were reported at visits 2, 3 , and 4 . Safety laboratory parameters were hemoglobin, hematocrit, erythrocytes, thrombocytes, leukocytes, creatinine, urea, uric acid, potassium, calcium (visits 1,4). Vital signs were evaluated throughout the study (visits 1-4).

\section{Compliance}

The volume of study water intake was documented in the diaries and controlled by the number of empty and full bottles returned.

\section{Efficacy Endpoints}

The primary efficacy endpoint was defined as the difference in the change of bowel movement frequency per week from baseline to visit 4 between the 2 groups. The main secondary efficacy endpoint was the difference in the change of bowel movement frequency per week from baseline to visit 3. Other secondary endpoints were the change in bowel movement frequency per week; stool consistency (BSFS); gastrointestinal well-being (GIQLI); general well-being (SF-12); liver and lipid metabolism function laboratory parameters; gut microbiota parameters; waist and hip circumferences; body weight; blood pressure; global evaluation of efficacy and tolerance by both investigators and participants; and safety laboratory parameters. 


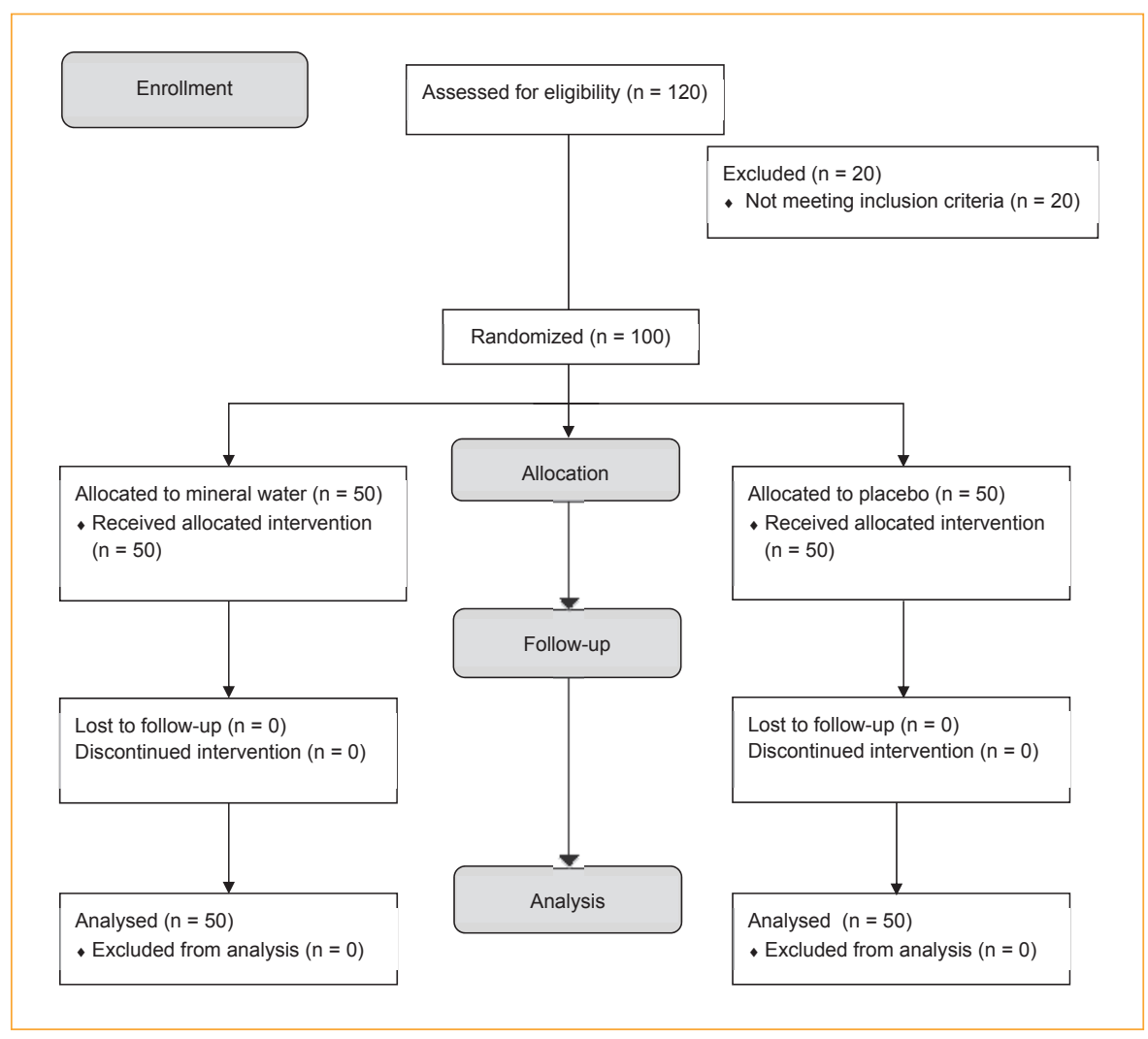

Fig. 1. Flow diagram of the participants.

\section{Results}

We expected a change in the frequency of bowel movements per week between baseline and visit 4 of 1.75 in the treatment group and of 0.5 in the control group (standard deviation $(\mathrm{SD})=2.0$ ). Thus, the difference is $1.25 \pm 2.0$ and the related effect size 0.62. Calculation was based on a Mann-Whitney U-test with an $\alpha$ risk level of 0.05 and a statistical power of $80 \%$, requiring 44 participants per group. With an expected dropout rate of $10 \%, 50$ participants per group were chosen.

\section{Randomization and Blinding}

Randomization codes (block of 4) were generated by an independent statistician with a computer program (BIAS, University Frankfurt/M., Germany). Study IDs were assigned chronologically on visit 2, when the participants received the first bottles of study water with the ID and randomization number printed on the label, ensuring that group assignment was concealed from both participants and investigators.

Participants, investigators, and the study team were blinded; the statistical analyses were performed blinded. The principal investigator was able to break the blind for serious AEs (SAE).

\section{Statistical Analyses}

The primary and secondary efficacy endpoints were analyzed by MannWhitney U-test, based on the intention-to-treat (ITT) population, defined as all randomized subjects having at least once taken the study water and from which efficacy data were documented, applying the last-observation-carried-forward (LOCF) approach to impute missing data. Baseline differences between the groups were assessed by either Mann-Whitney U-test or by $\chi^{2}$-test. Quantitative variables are described using the mean and $\mathrm{SD}$ for normally distributed values and the median for not normally distributed values. Qualitative variables are described using number and percentage. The level of significance was set at $\mathrm{P}<$ 0.05 . Statistical analyses were performed using SPSS ${ }^{\circledR}$, version 22 , for Windows $^{\mathrm{TM}}$ (version 9.2; SAS Institute).

\section{Population}

Details of the participant flow are given in figure 1. A total of 100 subjects were randomized to the treatment group (mineral water; $\mathrm{n}=50$ ) or the placebo group (tap water; $\mathrm{n}=50$ ). The subjects' mean $( \pm$ SD) age was $44.8 \pm 11.4$ years, with a significant difference ( $p=0.039)$ between the treatment group $(47.2 \pm 10.5$ years $)$ and the control group $(42.3 \pm 11.9$ years). Most of the participants were of Caucasian origin ( $n=99)$; only 1 was of Asian origin. There were no significant differences in other baseline characteristics (table 3).

\section{Efficacy Endpoints}

\section{Frequency of Bowel Movements}

After 6 weeks of treatment (primary endpoint), the change in the frequency of bowel movements per week with mineral water was $1.74 \pm 1.88$ compared to $1.22 \pm 1.72$ with placebo $(\mathrm{p}=0.163)$, showing a trend in favor of mineral water (fig. 2).

Statistical significance was reached after 3 weeks of treatment (main secondary endpoint) with mineral water, with a change in the frequency of bowel movements per week of $2.02 \pm 2.22$ compared to $0.88 \pm 1.67$ with placebo $(\mathrm{p}=0.005)$ (table 4$)$. This result was still significant after correcting for multiple testing according to Bonferroni, with the bowel movement frequency per week between baseline and visits 3 and 4 as variables (required $\mathrm{p}<0.025$ ). 
Table 3. Baseline demographic and clinical characteristics of the ITT population $(\mathrm{N}=100)$

\begin{tabular}{|c|c|c|c|c|}
\hline & $\begin{array}{l}\text { Overall, } \\
\mathrm{N}=100\end{array}$ & $\begin{array}{l}\text { Sulfate-rich mineral } \\
\text { water, } N=50\end{array}$ & $\begin{array}{l}\text { Placebo (tap water), } \\
\mathrm{N}=50\end{array}$ & $\mathrm{p}$ \\
\hline Gender (female/male) & $85 / 15$ & $42 / 8$ & $43 / 7$ & $0.779^{\$}$ \\
\hline Age, years & $44.8 \pm 11.4$ & $47.2 \pm 10.5$ & $42.3 \pm 11.9$ & $0.039^{\star \$}$ \\
\hline Height, $\mathrm{cm}$ & $170 \pm 8.1$ & $170.0 \pm 7.7$ & $170.0 \pm 8.5$ & $0.877^{\S}$ \\
\hline Weight, kg & $68.3 \pm 11.7$ & $68.5 \pm 11.9$ & $68.2 \pm 11.7$ & $0.642^{\S}$ \\
\hline BMI, $\mathrm{kg} / \mathrm{m}^{2}$ & $23.7 \pm 2.9$ & $23.7 \pm 3.0$ & $23.7 \pm 2.8$ & $0.825^{\S}$ \\
\hline Frequency of bowel movements per week & $2.86 \pm 1.00$ & $2.78 \pm 0.98$ & $2.94 \pm 1.02$ & $0.330^{\S}$ \\
\hline Stool consistency (BSFS) & $2.18 \pm 0.91$ & $2.29 \pm 0.96$ & $2.07 \pm 0.86$ & $0.191^{\S}$ \\
\hline
\end{tabular}

ITT = Intention-to-treat; BMI = body mass index; BSFS = Bristol Stool Form Scale (7-point scale ranging from the discrete lumps of slow transit (type 1,2) to the non-cohesive (type 6) and liquid stools (type 7) of rapid transit; types 3-5, normal stool); SD = standard deviation.

Data are shown as mean \pm SD.

${ }^{\$} \chi^{2}$-test.

${ }^{\S}$ Mann-Whitney U-test.

${ }^{*} \mathrm{p}<0.05$.
Fig. 2. Frequency of bowel movements per week $(\mathrm{N}=100)$. Data are shown as mean and SEM (standard error of the mean); ${ }^{*} \mathrm{p}<0.05$.

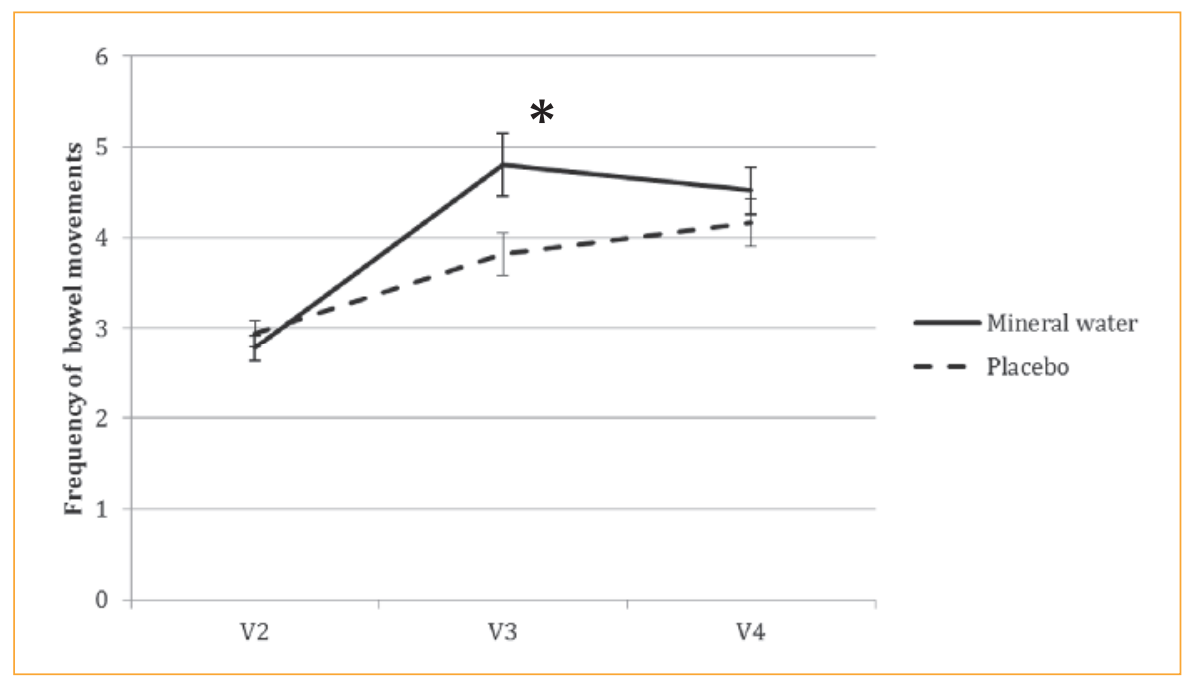

Further Secondary Efficacy Endpoints

Several endpoints were significantly improved in the mineral water group as compared with the placebo group: the bowel movement frequency per week (mineral water 4.8 , placebo 3.8 ; $\mathrm{p}=$ 0.036 ) and the stool consistency (BSFS) (mineral water 3.1, placebo $2.7 ; \mathrm{p}=0.044)$ (visit 3 ). At visit 4 , there was an improvement in the GIQLI subdimension 'physical functions' (change from baseline: mineral water 2.4, placebo $0.9 ; \mathrm{p}=0.015$ ) as well as in the SF-12 subdimension 'physical functions' (change from baseline: mineral water 2.1, placebo $-1.1 ; p=0.006$ ). The global evaluation of efficacy and tolerance by the investigators and the subjects (values in brackets) showed congruence in $94 \%$ of the cases for efficacy and $93 \%$ of the cases for tolerance. The efficacy was rated as very good in $19 \%(19 \%)$ of the cases, good in $30 \%$ (27\%), moderate in $42 \%$ $(45 \%)$, and poor in $9 \%(9 \%)$. Tolerance was rated as very good in $77 \%(72 \%)$ of the cases, good in $22 \%(25 \%)$, moderate in $1 \%(3 \%)$, and poor in $0 \%(0 \%)$. There were no differences between the groups. Liver and lipid parameters as well as the gut microbiota showed minor changes; these were, however, not clinically relevant (see Online Supplemental Text 2; www.karger.com/?DOI=449436). There were no differences $(\mathrm{p}<0.05)$ for the other secondary endpoints.

\section{Ancillary Analyses}

The relief of subjective symptoms, as documented in the patients' self-evaluation diaries, was greater in the treatment group than in the placebo group. At visit 3, the percentage of bowel movements with sensation of complete evacuation had increased (mineral water $54 \%$, placebo $37 \%$; $=0.014$ ) and the percentage of subjects with feeling of rectal pressure had decreased (mineral water $34 \%$, placebo $47 \%$; $\mathrm{p}=0.002$ ). However, the degree of pain during bowel movements was reduced in both groups $(\mathrm{p}<0.001)$. At the end of the treatment, $80 \%$ of the participants in the treatment group and $74 \%$ in the placebo group reported less pain $(\mathrm{p}<0.33)$.

\section{Compliance}

Compliance with treatment was very good: $3 \pm 5.4 \%$ of the provided water was returned after the study (mineral water $2.2 \pm 4.9 \%$, 
Table 4. Frequency of bowel movements of the ITT population $(\mathrm{N}=100)$

\begin{tabular}{llll}
\hline & $\begin{array}{l}\text { Sulfate-rich mineral } \\
\text { water }\end{array}$ & Placebo (tap water) & $\mathrm{p}^{\S}$ \\
\hline V2 (baseline) & $2.78 \pm 0.98$ & $2.94 \pm 1.02$ & 0.330 \\
V3 (after 3 weeks) & $4.80 \pm 2.46$ & $3.82 \pm 1.65$ & $0.036^{*}$ \\
V4 (after 6 weeks) & $4.52 \pm 1.85$ & $4.16 \pm 1.83$ & 0.357 \\
Difference V2 - V4 & $1.74 \pm 1.88$ & $1.22 \pm 1.72$ & 0.163 \\
Difference V2 - V3 & $2.02 \pm 2.22$ & $0.88 \pm 1.67$ & $0.005^{*}$ \\
\hline
\end{tabular}

ITT = Intention-to-treat; V2 to V4 = visits 2-4; SD = standard deviation. Data are shown as mean \pm SD.

${ }^{5}$ Mann-Whitney U-test.

${ }^{1}$ Primary endpoint.

${ }^{2}$ Secondary endpoint. ${ }^{*} \mathrm{p}<0.05$. placebo $3.7 \pm 5.8 \%)$. The overall duration of the treatment was $43 \pm$ 1.4 days, with no significant difference between the groups.

\section{Safety}

A total of 10 AEs were reported by 8 subjects (2 subjects reported $2 \mathrm{AEs}$ ), of which 6 were classified as minor, 4 as moderate, and none as severe. A relationship with treatment (meteorism with mineral water and diarrhea with placebo) was deemed possible for 2 of the AEs classified as being minor.

\section{Discussion}

While there is a physiological and clinical rationale that sulfaterich mineral water can at least reduce constipation, this randomized controlled study failed to show an effect [9-11, 22]. Surprisingly, the primary endpoint at week 6 was negative. A significant effect could be shown for the main secondary endpoint at week 3, even after Bonferroni correction. This result is consistent with the findings of an earlier 4-week controlled trial in women with functional constipation with 1 1/day of Hèpar, a magnesium sulfate-rich mineral water similar to Ensinger Schiller Quelle (total mineralization content: $2,513 \mathrm{mg} / \mathrm{l}$ and 2,666 mg/l, respectively) [15]. As in our study, the primary endpoint was negative and statistical significance was only reached for the main secondary endpoint at week 2 .

Nevertheless, this result was unexpected and several possibilities merit discussion to explain our findings.

Additional intake of water: The non-significant result after 6 weeks was not due to the effect of mineral water being small, but to the underestimated effect of the additional intake of water, which resulted in an increase of 1.22 bowel movements per week rather than the 0.5 movements anticipated. As shown by the National Health and Nutrition Examination Survey [5], lower intake of water is associated with increased constipation. Therefore, increasing the water intake by $0.5 \mathrm{l} / \mathrm{day}$, as prescribed in this and other studies, could explain the surprisingly good results achieved in the placebo group $[5,23]$.
Carbonated tap water: Carbonated water showed positive effects in double-blind randomized controlled trials on functional dyspepsia and constipation, which may explain the relatively strong effect seen in the placebo group [24, 25].

Mineralization content: The sulfate and magnesium contents of the investigational product may be too low. A recent study showed that a Slovenian natural water with a high mineralization content of $13 \mathrm{~g} / \mathrm{l}$ (sulfate 2,000 mg/l, magnesium 1,000 mg/l, hydrogen carbonate $7,600 \mathrm{mg} / \mathrm{l}$, and others), significantly improved the bowel movement frequency and stool consistency in 75 constipated subjects, as compared to a water with low mineralization content $(<1 \mathrm{~g} / \mathrm{l})[14]$.

Unspecific effects: A problem commonly associated with studies of the treatment of FC and other functional gastrointestinal disorders is the high placebo response rate [26] in addition to unspecific effects; especially, regression to the mean may also have played a role [27].

\section{Strengths and Limitations}

The limitations of the current study include an inadequately estimated effect size. Underestimating the effect of additional water intake resulted in an insufficient sample size. The onset of treatment response was faster than expected and did not further improve during prolonged application, resulting in an inadequate primary endpoint. There was a significant difference in age at baseline and the prevalence of constipation increases with age [28]; however, there was no significant difference at baseline in the primary endpoint, bowel movement frequency. The validity of paper diary records is limited. Concerns about compliance with paper diaries include poor adherence and retrospective or just-before-avisit recording [29].

The strengths of the study are the randomized double-blind placebo-controlled design and the fact that there were no dropouts throughout the study period. Compliance was also very good. The population (otherwise healthy, constipated subjects) studied here can be regarded as representative of routine clinical practice. Although validity may be restricted, generalizability is good [30]. 


\section{Clinical Implications}

With an increase of 2.8 bowel movements per week at baseline to 4.80 after 3 weeks and 4.52 after 6 weeks, the improvement seen in the treatment group can be regarded as clinically relevant since 3 or more bowel movements a week is considered the low end of the range defining normal bowel function [31]. It is noteworthy that $1 \mathrm{l}$ /day of tap water resulted in a clinically relevant improvement after 6 weeks; with 1 1/day of sulfate-rich mineral water, this effect was already achieved after 3 weeks.

The adequate relief of subjective symptoms resulted in an increase in gastrointestinal and general well-being, as documented in the patients' self-evaluation diaries and the physical dimensions of the GIQLI and the SF-12. In summary, health-related quality of life improved.

Furthermore, as in other studies, use of the sulfate-rich mineral water was associated with a very good safety profile. No SAEs and only 10 mild or moderate AEs were reported, with 2 minor AEs possibly being related to the treatment (meteorism with mineral water and diarrhea with placebo). This is in accordance with a review showing an association between higher sulfate content in water and an increase in stool frequency, but no association with diarrhea up to $2,800 \mathrm{mg} / \mathrm{l}$ or other AEs, even in infants [32].

Sulfates have been shown to have positive effects on the gallbladder; however, the sulfate-rich mineral water investigated did not show effects on liver enzymes [33]. Similarly, there were no improvements on blood lipids either; however, the results produced by other studies of sulfate-containing mineral water on blood lipids are contradictory $[15,26]$.

\section{Conclusions}

A 3-week treatment with $1 \mathrm{l}$ /day of the sulfate-rich mineral water improved the frequency of bowel movements in subjects with FC compared with tap water; however, the difference was no longer significant after 6 weeks.
Larger and longer studies are required to further assess the benefits of using sulfate-rich mineral water for the treatment of FC. In future studies, it could be interesting to include more severely constipated patients than those investigated in this trial.

\section{Acknowledgements}

The study was designed and performed by analyze \& realize $\mathrm{GmbH}$, Berlin, Germany. The authors thank the principal investigator, Prof. Ralf Uebelhack. The statistical analyses were finalized by Norman Bitterlich, Medizin \& Service, Chemnitz, Germany. Since the data are of general interest and had not been published previously, Ensinger sought collaboration with the academic authors to review the study files and data. The authors vouch for the completeness and veracity of the data and data analyses.

\section{Online Supplemental Material}

Online Supplemental Table 1 Mineralization content of Ensinger Schiller Quelle mineral water

Online Supplemental Table 2 Mineralization content of the tap water control (placebo)

Online Supplemental Text 1 Exclusion Criteria: Complete List

Online Supplemental Text 2 Laboratory Analyses: Results of Further Secondary Efficacy Endpoints

To access the supplemental material please refer to www.karger. com/?DOI=449436

\section{Disclosure Statement}

This study was funded by Ensinger Mineral-Heilquellen, Vaihingen-Ensingen, Germany. The funder had no role in the study design, data collection and analysis, decision to publish, or preparation of the manuscript.

J.N. receives support from balneology organizations, such as Deutscher Heilbäderverband and Heilbäderverband Baden-Württemberg, and is a member of these organizations. None of the organizations financed this work.

J.N. and C.S. received honoraria from Ensinger for their analysis and critical review of the provided data. F.A. is employed by analyze \& realize $\mathrm{GmbH}$, Berlin. R.H. declares that he has no conflict of interest.

\section{References}

1 Suares NC, Ford AC: Prevalence of, and risk factors for, chronic idiopathic constipation in the community: systematic review and meta-analysis. Am J Gastroenterol 2011;106:1582-1591

2 Stewart WF, Liberman JN, Sandler RS, Woods MS, Stemhagen A, Chee E, et al.: Epidemiology of Constipation (EPOC) study in the United States: relation of clinical subtypes to sociodemographic features. Am J Gastroenterol 1999;94:3530-3540.

3 Nellesen D, Yee K, Chawla A, Lewis BE, Carson RT: A systematic review of the economic and humanistic burden of illness in irritable bowel syndrome and chronic constipation. J Manag Care Pharm 2013;19:755-764.

4 Collins BR, O'Brien L: Prevention and management of constipation in adults. Nurs Stand 2015;29:49-58.
5 Markland AD, Palsson O, Goode PS, Burgio KL, Busby-Whitehead J, Whitehead WE: Association of low dietary intake of fiber and liquids with constipation: evidence from the National Health and Nutrition Examination Survey. Am J Gastroenterol 2013;108:796803

6 Moss GA: Water and health: a forgotten connection? Perspect Public Health 2010;130:227-232.

7 Vu MK, Nouwens MA, Biemond I, Lamers CB, Masclee AA: The osmotic laxative magnesium sulphate activates the ileal brake. Aliment Pharmacol Ther 2000; 14:587-595.

8 Aslanabadi N, Habibi Asl B, Bakhshalizadeh B, Ghaderi F, Nemati M: Hypolipidemic activity of a natural mineral water rich in calcium, magnesium, and bicarbonate in hyperlipidemic adults. Adv Pharm Bull 2014;4:303307.
9 Fraioli A, Menunni G, Petraccia L, Fontana M, Nocchi S, Grassi M: Sulphate-bicarbonate mineral waters in the treatment of biliary and digestive tract diseases. Clin Ter 2010;161:163-168.

10 Gutenbrunner C: Handbuch der Heilwasser-Trinkkuren: Theorie und Praxis. Sonntag, Stuttgart, 1994.

11 Böhmer H, Resch H, Gutenbrunner C: Sulfat-Heilwasser - eine zeitgemäße medikamentöse Alternative? Phys Med Rehabil Kurortmed 1999;9:1-5.

12 Gutenbrunner C, Gundermann G: Kontrollierte Studie über die abführende Wirkung eines sulfathaltigen Heilwassers. Z Allg Med 1998;74:648-651.

13 Heizer WD, Sandler RS, Seal E, Murray SC, Busby MG, Schliebe BG, et al.: Intestinal effects of sulfate in drinking water on normal human subjects. Dig Dis Sci 1997; 42:1055-1061. 
14 Bothe G, Coh A, Auinger A: Efficacy and safety of a natural mineral water rich in magnesium and sulphate for bowel function: a double-blind, randomized, placebo-controlled study. Eur J Nutr 2015; in press, doi: 10.1007/s00394-015-1094-8.

15 Dupont C, Campagne A, Constant F: Efficacy and safety of a magnesium sulfate-rich natural mineral water for patients with functional constipation. Clin Gastroenterol Hepatol 2014;12:1280-1287.

16 Constant F, Morali A, Arnaud MJ, Delabroise AM, Thirion F, Matisse N, et al.: Treatment of idiopathic constipation in infants: comparative and randomized study of two mineral waters (60 cases). J Pediatr Gastroenterol Nutr 1999;28:551.

17 Longstreth GF, Thompson WG, Chey WD, Houghton LA, Mearin F, Spiller RC: Functional bowel disorders. Gastroenterology 2006;130:1480-1491.

18 Schulz KF, Altman DG, Moher D: CONSORT 2010 statement: updated guidelines for reporting parallel group randomized trials. Ann Intern Med 2010;152:726-732.

19 Lewis SJ, Heaton KW: Stool Form Scale as a usefu guide to intestinal transit time. Scand J Gastroenterol 1997;32:920-924

20 Eypasch E, Williams JI, Wood-Dauphinee S, Ure BM, Schmülling C, Neugebauer E, et al.: Gastrointestinal Quality of Life Index: development, validation and application of a new instrument. Br J Surg 1995;82:216-222.
21 Gandek B, Ware JE, Aaronson NK, Apolone G, Bjorner JB, Brazier JE, et al.: Cross-validation of item selection and scoring for the SF-12 Health Survey in nine countries: results from the IQOLA Project. J Clin Epidemiol 1998;51:1171-1178.

22 Heizer WD, Sandler RS, Seal E, Murray SC, Busby MG, Schliebe BG, et al.: Intestinal effects of sulfate in drinking water on normal human subjects. Dig Dis Sci 1997; 42:1055-1061.

23 Anti M, Pignataro G, Armuzzi A, Valenti A, Iascone E, Marmo R, et al.: Water supplementation enhances the effect of high-fiber diet on stool frequency and laxative consumption in adult patients with functional constipation. Hepatogastroenterology 1998;45:727-732.

24 Cuomo R, Grasso R, Sarnelli G, Capuano G, Nicolai E, Nardone G, et al.: Effects of carbonated water on functional dyspepsia and constipation. Eur J Gastroenterol Hepatol 2002;14:991-999.

25 Mun J-H, Jun SS: Effects of carbonated water intake on constipation in elderly patients following a cerebrovascular accident. J Korean Acad Nurs 2011;41:269-275.

26 Spiller RC: Problems and challenges in the design of irritable bowel syndrome clinical trials: experience from published trials. Am J Med 1999;107:91S-97S.

27 Walach H, Sadaghiani C, Dehm C, Bierman D: The therapeutic effect of clinical trials: understanding placebo response rates in clinical trials - a secondary analysis. BMC Med Res Methodol 2005;5:26.
28 Gallagher P, O'Mahony D: Constipation in old age Best Pract Res Clin Gastroenterol 2009;23:875-887.

29 Stone AA, Shiffman S, Schwartz JE, Broderick JE, Hufford MR: Patient non-compliance with paper diaries. BMJ 2002;324:1193-1194.

30 Verheggen FW, Nieman F, Jonkers R: Determinants of patient participation in clinical studies requiring informed consent: why patients enter a clinical trial. $\mathrm{Pa}$ tient Educ Couns 1998;35:111-125.

31 Camilleri M, Kerstens R, Rykx A, Vandeplassche L: A placebo-controlled trial of prucalopride for severe chronic constipation. N Engl J Med 2008;358:23442354

32 Backer LC: Assessing the acute gastrointestinal effects of ingesting naturally occurring, high levels of sulfate in drinking water. Crit Rev Clin Lab Sci 2000;37:389-400.

33 Corradini SG, Ferri F, Mordenti M, Iuliano L, Siciliano M, Burza MA, et al.: Beneficial effect of sulphate-bicarbonate-calcium water on gallstone risk and weight control. World J Gastroenterol 2012;18:930-937. 